\title{
The COPD assessment test and St George's Respiratory Questionnaire: are they equivalent in subjects with COPD?
}

This article was published in the following Dove Press journal:

International Journal of COPD

7 July 2016

Number of times this article has been viewed

\author{
Mariko Morishita-Katsu ${ }^{1,2}$ \\ Koichi Nishimura ${ }^{3}$ \\ Hiroyuki Taniguchi' \\ Tomoki Kimura' \\ Yasuhiro Kondoh' \\ Kensuke Kataoka' \\ Tomoya Ogawa ${ }^{4}$ \\ Fumiko Watanabe ${ }^{4}$ \\ Shinichi Arizono ${ }^{5}$ \\ Osamu Nishiyama ${ }^{6}$ \\ Kazuhito Nakayasu ${ }^{7}$ \\ Kazuyoshi Imaizumi ${ }^{8}$ \\ Yoshinori Hasegawa ${ }^{2}$ \\ 'Department of Respiratory \\ Medicine and Allergy, Tosei General \\ Hospital, Seto, Japan; ${ }^{2}$ Division of \\ Respiratory Medicine, Department \\ of Medicine, Nagoya University \\ Graduate School of Medicine, Nagoya, \\ Japan; ${ }^{3}$ Department of Pulmonary \\ Medicine, National Center for \\ Geriatrics and Gerontology, Obu, \\ Japan; ${ }^{4}$ Department of Rehabilitation, \\ Tosei General Hospital, Seto, Japan; \\ ${ }^{5}$ School of Rehabilitation Sciences, \\ Seirei Christopher University, \\ Hamamatsu, Japan; ${ }^{6}$ Department of \\ Respiratory Medicine and Allergology, \\ Kinki University School of Medicine, \\ Osakasayama, Japan; ${ }^{7}$ Data Research \\ Section, Kondo P.P. Inc., Osaka, Japan; \\ ${ }^{8}$ Department of Respiratory Medicine. \\ Fujita Health University, Nagoya, Japan
}

Correspondence: Hiroyuki Taniguchi Department of Respiratory Medicine and Allergy, Tosei General Hospital, I60 Nishioiwake-cho, Seto, Aichi, Japan Email taniguchi@tosei.or.jp
Background: The chronic obstructive pulmonary disease (COPD) assessment test (CAT) is a short questionnaire that has facilitated health status measurements in subjects with COPD. However, it remains controversial as to whether the CAT can be used as a suitable substitute for the St George's Respiratory Questionnaire (SGRQ). This study investigated the reliability and score distributions of the CAT and SGRQ and evaluated which factors contributed to health status for each questionnaire.

Methods: A total of 109 consecutive subjects with stable COPD from a single center were enrolled in this study. Each subject completed pulmonary function tests, exercise tests, and the following self-administered questionnaires: the Baseline Dyspnea Index, the Hospital Anxiety and Depression Scale, the CAT, and SGRQ.

Results: Internal consistencies of CAT and SGRQ total scores were both excellent (Cronbach's $\alpha$ coefficients $=0.890$ and 0.933 ). Statistically significant correlations were observed between CAT and SGRQ total scores $(R=0.668, P<0.001)$. Correlations of CAT scores with parameters related to pulmonary function, dyspnea, exercise performance, and psychological factors were inferior to correlations with those parameters with SGRQ total scores. Both multiple regression analyses and principal component analyses revealed that there were slight differences between SGRQ total scores and CAT scores.

Conclusion: The CAT is similar to SGRQ in terms of discriminating health status. However, we demonstrated that what is assessed by the CAT may differ slightly from what is measured by SGRQ.

Keywords: chronic obstructive pulmonary disease, St George's Respiratory Questionnaire, COPD assessment test, health status

\section{Background}

Health status measurements in chronic obstructive pulmonary disease (COPD) subjects can provide information on patient status that physiological evaluations cannot. Therefore, such information should be routinely assessed in clinical practice. To this end, over the past 2 decades, St George's Respiratory Questionnaire (SGRQ) and the Chronic Respiratory Disease Questionnaire have been extensively validated and used in clinical trials. ${ }^{1,2}$ However, these instruments are generally time consuming and complicated both in terms of calculating scores and in their application when time is limited. In light of the growing importance of measuring health status, a shorter and simpler method may be more appropriate for routine use. Jones et $\mathrm{al}^{3-5}$ developed a new and simple questionnaire called the COPD assessment test (CAT), to facilitate the application of health status measurements in subjects with COPD. The CAT has 
eight items, each formatted as a six-point differential scale, making the tool easy for medical professionals to administer and for patients to complete.

The CAT has been a key tool for patient assessments in the Global Initiative for Chronic Obstructive Lung Disease (GOLD), which was updated in $2011 .^{6}$ The CAT is a validated questionnaire that distinguishes patients with varying degrees of COPD severity and appears to behave similarly across countries. ${ }^{5,7}$ CAT scores also improve in response to pulmonary rehabilitation and can distinguish between categories of response. ${ }^{9,10}$

Although the evidence for expanding the use of the CAT in clinical practice has been accumulating worldwide, detailed information has not been published on the relationship of SGRQ and CAT scores with other disease-specific outcome markers; usually, only the overall correlation or CAT properties are reported in the literature. Although the CAT was carefully developed according to guidelines for patient-reported outcomes, using both qualitative and quantitative research steps, it is possible that the CAT may measure somewhat different concepts than SGRQ. Given this, it is important to determine if the CAT can be used as a suitable substitute for SGRQ.

Although some investigators consider health status to consist of four main domains (physiological functioning, symptoms, functional impairment, and quality of life), and at least 16 subdomains, it was reported that SGRQ is appropriate only for measuring problems in the subdomains of subjective symptoms and subjective impairment, and not for measuring problems in other subdomains of health status, such as quality of life. ${ }^{11}$ Since it is possible that the different components of health status could be assessed by the CAT, the authors intended to compare the CAT and SGRQ in terms of their ability to accurately reflect different components of health status using principal component analysis (PCA).

We hypothesized that the CAT is capable of accurately describing the health status of subjects with COPD. The purpose of this study was to compare measurement properties, especially the reliability, score distribution, and concurrent validity, of the CAT versus SGRQ. In addition, we evaluated the contribution of pulmonary function, exercise capacity, dyspnea rating, and psychological status to the health status of COPD subjects to highlight the contributing characteristics identified by the CAT versus SGRQ.

\section{Methods}

\section{Study design}

A total of 109 consecutive subjects with stable COPD, defined as a forced expiratory volume in 1 second $\left(\mathrm{FEV}_{1}\right)$ /forced vital capacity (FVC) of less than $70 \%$ in all previous measurements, were recruited from the outpatient clinic of the Department of Respiratory Medicine and Allergy at Tosei General Hospital. The entry criteria included the following: 1) a diagnosis of COPD and age over 50 years; 2) a smoking history of more than 10 pack-years; and 3) no obvious abnormal shadows on chest X-rays. Exclusion criteria were the following: patients with any history suggestive of another pulmonary disease, a history of lung surgery, an exacerbation of COPD over the preceding 3 months, any comorbid conditions likely to reduce exercise capacity (eg, musculoskeletal conditions, unstable heart disease, or neurologic impairment), or any other illnesses. Written informed consent was obtained from all subjects prior to their enrollment in the trial. On evaluation days, subjects completed pulmonary function tests, 6-minute walk tests, progressive cycle ergometer tests, and assessments of dyspnea, anxiety, depression, and health status. This study was approved by the ethics committee of Tosei General Hospital (approval number 309).

\section{Pulmonary function and exercise tests}

Spirometric flow-volume curves were recorded with subjects seated, according to a previously described method by the American Thoracic Society/European Respiratory Society Task Force in 2005. ${ }^{12}$ Predicted values for $\mathrm{FEV}_{1}$ and vital capacity (VC) were calculated according to proposals from the Japanese Society of Chest Diseases. ${ }^{13}$ Residual volume (RV) was measured with a closed-circuit helium method, and diffusion capacity for carbon monoxide (DLCO) was measured using a single-breath technique (CHESTAC-55V; Chest, Tokyo, Japan). Progressive exercise tests to symptomlimited maxima were performed using an electrically braked cycle ergometer (Ergometer 232CXL; Combi, Tokyo, Japan), as described by Arizono et al. ${ }^{14}$ The workload was increased by $10 \mathrm{~W}$ every minute after a 2-minute unloaded cycling, and patients maintained a pedaling rate of $60 \mathrm{rpm}$ throughout the test until they could no longer continue. Exercise data were recorded using an automated exercise testing system (CardioStar; Fukuda Denshi, Tokyo, Japan). Minute ventilation and oxygen tension in expired air were determined, and mean minute ventilation and oxygen uptake $\left(V^{\prime} \mathrm{O}_{2}\right)$ were calculated. Peak values were defined as those averaged during the last 30 seconds of the highest workload achieved. Six-minute walk tests were performed in a hospital corridor 50 m long. ${ }^{15}$ We emphasized to patients that the aim of the test was to walk as far as they could in 6 minutes, and standardized encouragement was provided throughout the tests. Borg scores (0-10) for evaluating symptoms of 
breathlessness were recorded at rest and immediately after walking cessation. The distance they covered was measured as the 6-minute walk distance (6MWD). Each walk test was repeated twice, and the longest distance walked was used in the analysis. While all 109 subjects underwent pulmonary function and 6-minute walk tests, progressive exercise tests were completed in 104 participants.

\section{Patient questionnaires}

A validated Japanese version of the Baseline Dyspnea Index (BDI) was used to assess dyspnea. ${ }^{16,17}$ The BDI recognizes five grades for each of the following categories: functional impairment, magnitude of task, and magnitude of effort, with higher scores indicating more severe dyspnea. The first two studies for the validation of the original Japanese version of the BDI were published in 1998. ${ }^{16,18}$ A newer Japanese version of the BDI was subsequently developed and replaced the older version in 2008. However, the former Japanese version of the BDI was used in this study. Dyspnea was evaluated by the modified Medical Research Council (mMRC) dyspnea scale, which uses a five-point scale. The Japanese version of the Hospital Anxiety and Depression Scale (HADS) was used for evaluating anxiety and depression status. The HADS consists of 14 items, seven scoring for anxiety and seven for depression. The HADS was scored in accordance with the methods reported by the original author. ${ }^{19}$ Health status was assessed with previously validated Japanese versions of the CAT and SGRQ (version 1). ${ }^{8,16}$ CAT scores range from 0 to 40 , with a score of 0 indicating no impairment. The scores of three components (symptoms, activity, and impact) of SGRQ were obtained but not analyzed herein since they were not developed to be evaluated separately from total scores and would not add anything new to the analysis. The CAT, SGRQ, BDI, mMRC, and HADS were self-administered under site supervision in the aforementioned order (in booklet form).

\section{Statistical analyses}

All results are expressed as mean \pm standard deviation. Missing SGRQ items were handled according to the developers' instructions in the SGRQ manual. Relationships between two sets of data were analyzed by Pearson's correlation tests. ANOVA and Tukey's honestly significant difference tests were used to compare CAT and SGRQ scores between groups. In addition, relationships of CAT and SGRQ scores with the degree of airflow limitation were analyzed by JonckheereTerpstra trend tests. Physiological measures were compared when the two tests had inconsistent findings using MannWhitney's $U$-test. To identify variables that influenced CAT and SGRQ total scores, a stepwise forward regression method (method of increasing and decreasing variables) was conducted, as previously described elsewhere. ${ }^{16,20}$ Independent variables were selected from those that significantly correlated with CAT and SGRQ total scores in univariate analyses. However, to avoid multicolinearity, only one of the highly correlated variables was entered in the multivariate model, if present. Independent variables were as follows: age (years), smoking (pack-years), body mass index (BMI; $\mathrm{kg} / \mathrm{m}^{2}$ ), $\mathrm{FEV}_{1}$ (\% pred), RV/total lung capacity (TLC; \%), the $\mathrm{D}_{\mathrm{LCO}}$ divided by the alveolar volume $\left(\mathrm{D}_{\mathrm{LCO}} / \mathrm{V}_{\mathrm{A}}\right)(\mathrm{mL} / \mathrm{min} / \mathrm{mmHg} / \mathrm{L})$, 6MWD (m), BDI scores, and depression scores on HADS. The internal consistency of each questionnaire was assessed with Cronbach's $\alpha$ coefficient. The $95 \%$ confidence interval of Cronbach's $\alpha$ coefficient was calculated with psychometric Package R, version 3.0.2 (R Core Team 2013. R: a language and environment for statistical computing. R Foundation for Statistical Computing, Vienna, Austria). ${ }^{21}$ In addition, PCA was performed to identify components that best describe patient's health and to identify groups of variables that best correlate with each component, by examining the relative contribution of the variables described earlier to CAT and SGRQ total scores. ${ }^{22,23}$ A $P$-value of less than 0.05 was considered to be statistically significant.

\section{Results}

A total of 109 consecutive subjects (104 males) were studied between January 2010 and September 2011. While 91 subjects quit smoking more than half a year before the study, 18 were current smokers. Demographic details as well as pulmonary function test results are listed in Table 1. The average age was $70.6 \pm 6.8$ years, and the average $\mathrm{FEV}_{1}$ was $1.06 \pm 0.46 \mathrm{~L}$, which is indicative of the fact that the group included cases with mild-to-severe airflow limitation. All but five patients were treated with inhaled bronchodilators and/or inhaled corticosteroids. Thirteen patients were treated with long-term oxygen therapy. Nine subjects were managed with noninvasive positive pressure ventilation at home.

The score distribution and internal consistency assessed with Cronbach's $\alpha$ coefficient for CAT and SGRQ scores in this study are listed in Table 2. The internal consistency of the CAT was high (Cronbach's $\alpha$ coefficient $=0.890$ ), and the coefficient for SGRQ was also high $(\alpha=0.933)$. Floor and ceiling effects were not seen. Figure 1 shows frequency distribution histograms and cumulative frequency distribution curves of CAT and SGRQ total scores. 
Table I Demographic details and pulmonary function tests and their correlations (Pearson's correlation coefficients) with CAT and SGRQ total scores in 109 consecutive subjects (104 males) with stable COPD

\begin{tabular}{|c|c|c|c|c|c|c|}
\hline & \multirow[t]{2}{*}{ Mean } & \multirow[t]{2}{*}{ SD } & \multirow[t]{2}{*}{ Max } & \multirow[t]{2}{*}{ Min } & \multicolumn{2}{|c|}{ Correlation coefficient $(R)$ with } \\
\hline & & & & & CAT score & SGRQ total score \\
\hline Age (years) & 70.6 & 6.8 & 87.0 & 53.0 & - & - \\
\hline BMI $\left(\mathrm{kg} / \mathrm{m}^{2}\right)$ & 20.9 & 3.4 & 30.5 & 13.5 & - & - \\
\hline Cumulative smoking (pack-years) & 69 & 35 & 198 & 13 & - & - \\
\hline VC (L) & 2.88 & 0.64 & 4.68 & 1.76 & - & $-0.295^{\mathrm{a}}$ \\
\hline VC (\% pred) & 90.8 & 16.6 & 138.3 & 57.3 & - & $-0.397^{\mathrm{b}}$ \\
\hline FVC (L) & 2.80 & 0.65 & 4.54 & 1.62 & - & $-0.315^{\mathrm{a}}$ \\
\hline FVC (\% pred) & 88.2 & 17.5 & 136.6 & 50.6 & - & $-0.410^{b}$ \\
\hline $\mathrm{FEV}_{1}(\mathrm{~L})$ & 1.06 & 0.46 & 2.35 & 0.41 & $-0.359^{b}$ & $-0.533^{b}$ \\
\hline $\mathrm{FEV}_{1}(\%$ pred $)$ & 47.8 & 19.6 & 102.8 & 13.0 & $-0.414^{b}$ & $-0.540^{b}$ \\
\hline $\mathrm{FEV}_{\mathrm{I}} / \mathrm{FVC}(\%)$ & 37.3 & 11.7 & 68.9 & 19.3 & $-0.436^{\mathrm{b}}$ & $-0.491^{\mathrm{b}}$ \\
\hline $\mathrm{RV}(\mathrm{L})$ & 2.61 & 0.80 & 5.27 & 1.06 & $0.234^{c}$ & $0.257^{\mathrm{a}}$ \\
\hline RV (\% pred) & 158.1 & 49.4 & 376.4 & 63.9 & $0.200^{c}$ & $0.236^{c}$ \\
\hline RV/TLC (\%) & 46.8 & 9.6 & 70.9 & 26.2 & $0.244^{c}$ & $0.374^{b}$ \\
\hline $\mathrm{DLCO}(\mathrm{mL} / \mathrm{min} / \mathrm{mmHg})$ & 8.16 & 3.54 & 21.39 & 1.47 & - & $-0.323^{\mathrm{a}}$ \\
\hline DLCO (\% pred) & 56.9 & 20.3 & 114.3 & 8.9 & - & $-0.31 I^{a}$ \\
\hline $\mathrm{DLCO} / \mathrm{V}_{\mathrm{A}}(\mathrm{mL} / \mathrm{min} / \mathrm{mmHg} / \mathrm{L})$ & 1.90 & 0.80 & 4.46 & 0.36 & $-0.208^{c}$ & $-0.349^{b}$ \\
\hline
\end{tabular}

Notes: Missing values are not statistically significant. ${ }^{a} P<0.01$, ${ }^{b} P<0.001$, $c P<0.05$.

Abbreviations: CAT, COPD assessment test; COPD, chronic obstructive pulmonary disease; SGRQ, St George's Respiratory Questionnaire; SD, standard deviation; Max, maximum; Min, minimum; BMI, body mass index; VC, vital capacity; FVC, forced vital capacity; FEV , forced expiratory volume in I second; RV, residual volume; TLC, total lung capacity; DLCO, diffusion capacity for carbon monoxide; $\mathrm{D}_{\mathrm{LCO}} / \mathrm{V}_{\mathrm{A}}, \mathrm{D}_{\mathrm{LCO}}$ divided by the alveolar volume.

The total score of the SGRQ was $27.3 \pm 17.3$ in nine subjects with mild airflow limitation (GOLD 1), $32.8 \pm 18.8$ in 33 subjects with moderate airflow limitation (GOLD 2), $48.0 \pm 15.4$ in 46 subjects with severe airflow limitation (GOLD 3), and 57.9 \pm 16.0 in 21 subjects with very severe airflow limitation (GOLD 4). The SGRQ total score significantly differed by the degree of airflow limitation (GOLD 1 vs 3, $P=0.005$; GOLD 1 vs $4, P<0.001$; GOLD 2 vs $3, P=0.001$; GOLD 2 vs $4, P<0.001$ and also $P<0.001$ by the JonckheereTerpstra trend test). Although there was a wide range of CAT scores for each degree of airflow limitation $(10.3 \pm 8.0$, $13.1 \pm 6.5,16.9 \pm 8.4$, and $21.7 \pm 8.5$ for GOLD $1-4$, respectively), scores were also significantly different for different degrees of airflow limitation (ie, GOLD 1 vs $4, P=0.003$; GOLD 2 vs $4, P=0.001$ and $P<0.001$ by the JonckheereTerpstra trend test). CAT scores significantly correlated with SGRQ total scores $(R=0.668, P<0.001$; Figure 2$)$.
The data were also analyzed to understand the impact of discordance in the distributions of CAT and SGRQ total scores. If a CAT score of greater than or equal to 10 , or a SGRQ total score over 25, was considered to indicate a high level of symptoms, the number of individuals with good CAT and bad SGRQ scores was 17 (15.6\%) and the number of individuals with good SGRQ and bad CAT scores was 10 (9.2\%). Physiological measures were compared between these 27 patients with discordant SGRQ and CAT scores and the 82 patients whose $S G R Q$ and $C A T$ scores were in accord. $\mathrm{FEV}_{1}$, $\mathrm{FEV}_{1} / \mathrm{FVC}, \mathrm{MRC}, \mathrm{BDI}$, and 6MWD were significantly different between the two groups (all $P<0.01$, Mann-Whitney's $U$-test), indicating that the discordance of the CAT and SGRQ total scores is associated with milder impairment.

With respect to relationships with physiological parameters, Pearson's correlation coefficients between the CAT and other variables were compared with similar correlations

Table 2 The internal consistency assessed with Cronbach's $\alpha$ coefficient and score distributions of CAT and SGRQ total scores in I09 consecutive subjects with stable COPD

\begin{tabular}{|c|c|c|c|c|c|c|c|c|}
\hline & \multirow{2}{*}{$\begin{array}{l}\text { Possible } \\
\text { score range }\end{array}$} & \multirow[t]{2}{*}{ Items (n) } & \multirow{2}{*}{$\begin{array}{l}\text { Cronbach's } \alpha \\
\text { coefficient }(95 \% \mathrm{Cl})\end{array}$} & \multicolumn{5}{|c|}{ Score distribution } \\
\hline & & & & Mean & SD & Median & Max & Min \\
\hline CAT & $(0-40)$ & 8 & $0.890(0.856-0.919)$ & 16.1 & 8.5 & 16 & 38 & 1 \\
\hline SGRQ total & $(0-100)$ & 50 & $0.933(0.914-0.950)$ & 43.6 & 19.5 & 43.9 & 84.7 & 1.9 \\
\hline
\end{tabular}

Abbreviations: CAT, COPD assessment test; COPD, chronic obstructive pulmonary disease; SGRQ, St George's Respiratory Questionnaire; Cl, confidence interval; $\mathrm{SD}$, standard deviation; Max, maximum; Min, minimum. 
A

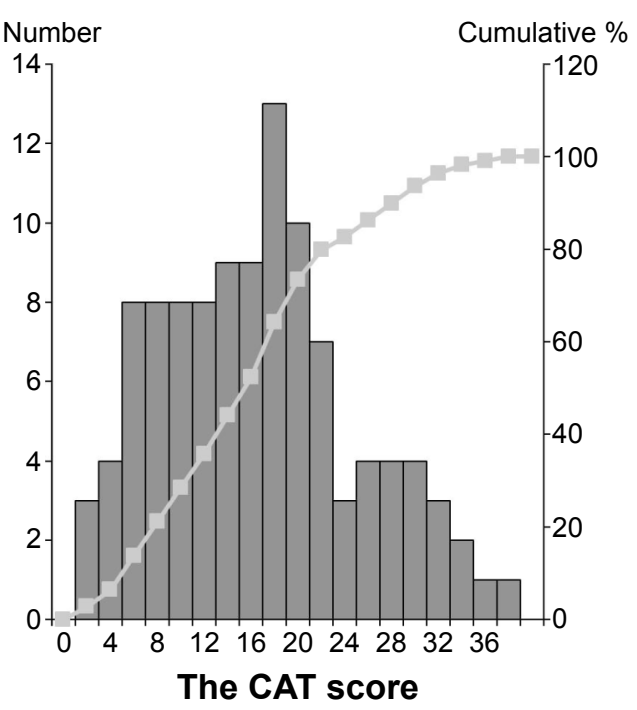

B

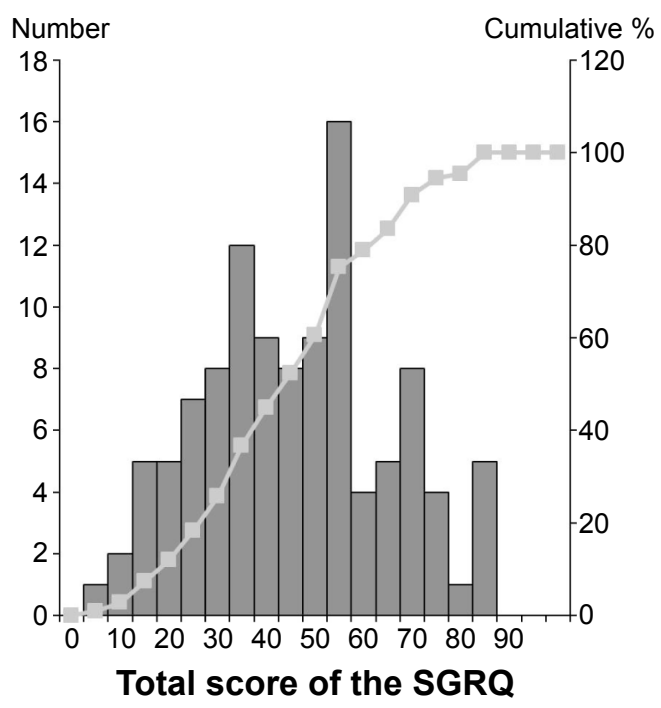

Figure I Frequency distribution histograms and cumulative frequency distribution curves of CAT (A) and SGRQ (B) total scores in I09 consecutive subjects with stable COPD.

Notes: The bars show the frequency distribution for each score. Line plots indicate the cumulative percentage of patients.

Abbreviations: CAT, COPD assessment test; COPD, chronic obstructive pulmonary disease; SGRQ, St George's Respiratory Questionnaire.

for SGRQ (Table 1). The CAT score significantly correlated with $\mathrm{FEV}_{1}(\mathrm{~L}), \mathrm{FEV}_{1}\left(\%\right.$ pred), $\mathrm{FEV}_{1} / \mathrm{FVC}(\%)$, and DLCO/ $\mathrm{V}_{\mathrm{A}}(\mathrm{mL} / \mathrm{min} / \mathrm{mmHg} / \mathrm{L})$, but not with SVC, FVC, or DLCO. The SGRQ total score significantly correlated with all of the variables obtained from pulmonary function tests (Table 1). In addition, correlations of SGRQ total scores with all the physiological parameters were superior to those of CAT scores.

In relation to dyspnea, both CAT and SGRQ total scores significantly correlated with the $\mathrm{mMRC}, \mathrm{BDI}$, and Borg scores

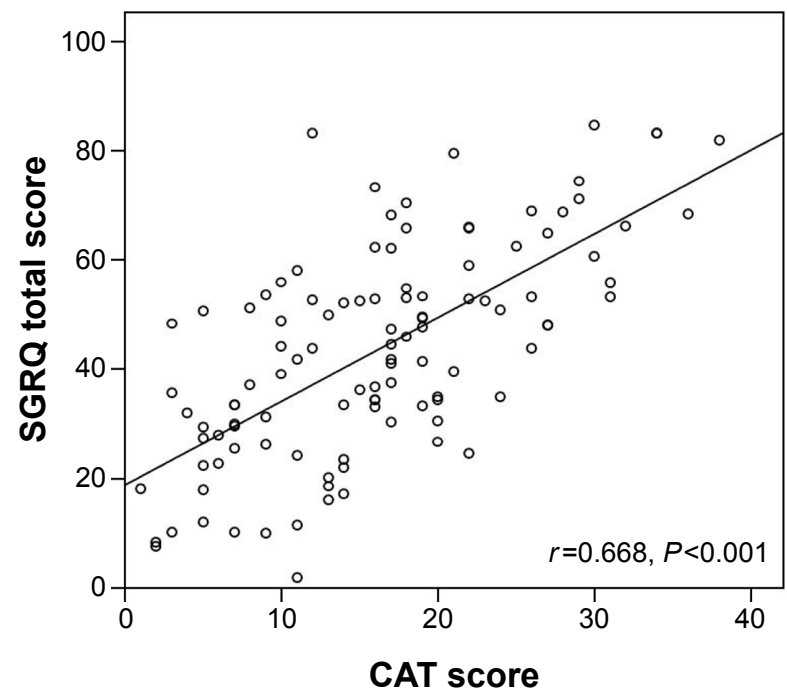

Figure 2 Scatter plot of the correlation between the CAT score and the SGRQ total score.

Abbreviations: CAT, COPD assessment test; COPD, chronic obstructive pulmonary disease; SGRQ, St George's Respiratory Questionnaire. at the end of exercise (Table 3). With respect to exercise performance, CAT and SGRQ total scores significantly correlated with 6MWD and peak $V^{\prime} \mathrm{O}_{2}$ (Table 3). With respect to psychological factors, CAT and SGRQ total scores significantly correlated with anxiety and depression on HADS (Table 3). However, correlations of SGRQ total scores with all parameters related to dyspnea, exercise performance, and psychological factors were superior to those of CAT scores.

Stepwise multiple regression analyses were performed to identify variables that could best predict CAT and SGRQ total scores (Table 4). Variables such as FEV (\% pred), DLCO $/ \mathrm{V}_{\mathrm{A}}$ (mL/min $/ \mathrm{mmHg} / \mathrm{L}$ ), 6MWD (m), BDI score, and the depression score on HADS were adopted as independent variables in the regression analyses, since they characteristically had the strongest univariate correlations with CAT and SGRQ total scores, as listed in Tables 1 and 3. We found that dyspnea assessed by BDI and depression on HADS significantly accounted for CAT scores. Since the cumulative $R^{2}$ was 0.366 , unknown factors also contribute to CAT scores. On the other hand, in addition to dyspnea and psychological factors, airflow limitation assessed by $\mathrm{FEV}_{1}$ and exercise capacity assessed by 6MWD were significant contributors, accounting for $63.0 \%$ of the variance in SGRQ total scores.

To examine the structure of CAT and SGRQ total scores, the aforementioned nine variables were subjected to principal components analyses. Kaiser's criterion of eigenvalue $>1$ was used to determine the number of components. PCA revealed 
Table 3 Exercise performance, dyspnea, psychological factors, and their correlations (Pearson's correlation coefficients) with CAT and SGRQ total scores in 109 consecutive subjects with stable COPD

\begin{tabular}{|c|c|c|c|c|c|c|}
\hline & \multirow[t]{2}{*}{ Mean } & \multirow[t]{2}{*}{ SD } & \multirow[t]{2}{*}{ Max } & \multirow[t]{2}{*}{ Min } & \multicolumn{2}{|c|}{ Correlation coefficient $(R)$ with } \\
\hline & & & & & CAT score & SGRQ total score \\
\hline \multicolumn{7}{|l|}{ Exercise performance } \\
\hline 6MWD (m) & 463 & 129 & 740 & 100 & -0.393 & -0.625 \\
\hline $\mathrm{VO}_{2} \mathrm{max}^{\mathrm{a}}(\mathrm{mL} / \mathrm{min} / \mathrm{kg})$ & 13.6 & 3.8 & 23.2 & 5.0 & -0.374 & -0.561 \\
\hline \multicolumn{7}{|l|}{ Dyspnea } \\
\hline BDI score $(0-12)$ & 7.3 & 2.7 & 12 & 0 & -0.564 & -0.663 \\
\hline $\mathrm{mMRC}(0-4)$ & 1.7 & 1.0 & 4 & 0 & 0.476 & 0.637 \\
\hline Borg score at the end of exercise $(0-10)$ & 5.6 & 2.4 & 10 & 0.5 & 0.519 & 0.507 \\
\hline \multicolumn{7}{|l|}{ Psychological factors } \\
\hline Anxiety on HADS (0-2I) & 5.2 & 3.8 & 15 & 0 & 0.388 & 0.464 \\
\hline Depression on HADS $(0-2 I)$ & 6.3 & 3.6 & 16 & 0 & 0.464 & 0.572 \\
\hline
\end{tabular}

Notes: All correlations are statistically significant $(P<0.001) .{ }^{\mathrm{a}} \mathrm{n}=105$.

Abbreviations: CAT, COPD assessment test; COPD, chronic obstructive pulmonary disease; SGRQ, St George's Respiratory Questionnaire; SD, standard deviation; Max, maximum; Min, minimum; 6MWD, 6-minute walk distance; BDI, Baseline Dyspnea Index; mMRC, modified Medical Research Council; HADS, Hospital Anxiety and Depression Scale.

the presence of three components. Component 1 accounted for $34 \%$ of the variance, component 2 for $17 \%$, and component 3 for 13\% (Table 5). Most variables describing exercise, dyspnea, and pulmonary function loaded mainly on component 1 (pathophysiologic component), variables describing age and BMI loaded on component 2 (background component), and the variable describing cumulative smoking loaded on component 3 (smoking component), as listed in Table 6. The correlation of component 1 with SGRQ total scores was superior to that of the correlation with CAT scores (Table 7). The correlation of component 3 with SGRQ total scores was not statically significant, although the CAT score

Table 4 Results of stepwise multiple regression analyses to identify variables that could best predict CAT and SGRQ total scores in 109 consecutive subjects with stable COPD

\begin{tabular}{|c|c|c|}
\hline & $\begin{array}{l}\text { CAT } \\
\text { score }\end{array}$ & $\begin{array}{l}\text { SGRQ } \\
\text { total score }\end{array}$ \\
\hline \multicolumn{3}{|l|}{ Independent variables } \\
\hline Age (years) & - & - \\
\hline Smoking (pack-years) & - & - \\
\hline BMI $\left(\mathrm{kg} / \mathrm{m}^{2}\right)$ & - & - \\
\hline $\mathrm{FEV}_{1}$ (\% pred) & - & $-0.224^{a}$ \\
\hline RV/TLC (\%) & - & - \\
\hline $\mathrm{DLCO} / \mathrm{V}_{\mathrm{A}}(\mathrm{mL} / \mathrm{min} / \mathrm{mmHg} / \mathrm{L})$ & - & - \\
\hline 6MWD $(m)$ & - & $-0.283^{b}$ \\
\hline BDI score & $-0.443^{b}$ & $-0.26 I^{a}$ \\
\hline Depression score on HADS & $0.25 \mathrm{I}^{\mathrm{a}}$ & $0.278^{\mathrm{b}}$ \\
\hline Cumulative $R^{2}$ & 0.366 & 0.630 \\
\hline \multicolumn{3}{|c|}{$\begin{array}{l}\text { Notes: Missing values are not statistically significant. }{ }^{\mathrm{a}}<<0.0 \mathrm{I},{ }^{\mathrm{b}}<0.00 \mathrm{I} \text {. } \\
\text { Abbreviations: CAT, COPD assessment test; COPD, chronic obstructive } \\
\text { pulmonary disease; SGRQ, St George's Respiratory Questionnaire; BMI, body } \\
\text { mass index; FEV }{ }_{1} \text {, forced expiratory volume in I second; RV, residual volume; } \\
\text { TLC, total lung capacity; DLCO, diffusion capacity for carbon monoxide; } 6 \mathrm{MWD} \text {, } \\
\text { 6-minute walk distance; BDI, Baseline Dyspnea Index; HADS, Hospital Anxiety and } \\
\text { Depression Scale; } D_{\text {LCO }} \mathrm{N}_{\mathrm{A}} \text {, } \mathrm{D}_{\text {LCO }} \text { divided by the alveolar volume. }\end{array}$} \\
\hline
\end{tabular}

significantly correlated with component 3 . Therefore, PCA demonstrated three different components that significantly accounted for variations in the CAT, although only two of them significantly accounted for variations in the SGRQ.

\section{Discussion}

To our knowledge, this is the first report to systematically compare measurement properties of the CAT and SGRQ in subjects with stable COPD. Our analysis of health status measurements using the CAT and SGRQ revealed two important findings. First, the CAT is valid as compared to SGRQ, since the internal consistency and score distribution of both questionnaires were exemplary and nearly identical. Second, contributing factors identified by stepwise multiple regression analyses differed to some degree between CAT and SGRQ total scores. In addition, PCA demonstrated a stronger correlation between the contributing factors and SGRQ total scores, although component 1 (pathophysiologic component) correlated with both CAT and SGRQ total

Table 5 Principal component analyses

\begin{tabular}{llll}
\hline Component & Eigenvalue & $\begin{array}{l}\text { Contribution } \\
\text { ratio }\end{array}$ & $\begin{array}{l}\text { Cumulative } \\
\text { contribution ratio }\end{array}$ \\
\hline 1 & 3.029 & 33.653 & 33.653 \\
2 & 1.551 & 17.230 & 50.883 \\
3 & 1.149 & 12.770 & 63.653 \\
4 & 0.940 & 10.440 & 74.093 \\
5 & 0.781 & 8.681 & 82.774 \\
6 & 0.598 & 6.643 & 89.416 \\
7 & 0.446 & 4.951 & 94.367 \\
8 & 0.290 & 3.218 & 97.586 \\
9 & 0.217 & 2.414 & 100.000 \\
\hline
\end{tabular}

Note: Three factors had eigenvalues $>I$ and explained $63.7 \%$ of the variance. 
Table 6 Principal component loadings

\begin{tabular}{|c|c|c|c|}
\hline \multirow[t]{2}{*}{ Variables } & \multicolumn{3}{|c|}{ Components } \\
\hline & $\mathbf{I}$ & 2 & 3 \\
\hline Age (years) & -0.176 & 0.706 & -0.395 \\
\hline Smoking (pack-years) & -0.113 & 0.266 & 0.530 \\
\hline BMI $\left(\mathrm{kg} / \mathrm{m}^{2}\right)$ & 0.502 & -0.533 & -0.175 \\
\hline $\mathrm{FEV}_{1}$ (\% pred) & 0.657 & 0.481 & -0.349 \\
\hline RV/TLC (\%) & -0.679 & -0.044 & 0.481 \\
\hline $\mathrm{DLCO} / \mathrm{V}_{\mathrm{A}}(\mathrm{mL} / \mathrm{min} / \mathrm{mmHg} / \mathrm{L})$ & 0.647 & -0.433 & -0.024 \\
\hline 6MWD (m) & 0.788 & -0.120 & 0.275 \\
\hline BDI score & 0.721 & 0.351 & 0.306 \\
\hline Depression score on HADS & -0.529 & -0.373 & -0.398 \\
\hline
\end{tabular}

Note: Scores with factor loadings $>0.50$ are shown in bold.

Abbreviations: $\mathrm{BMI}$, body mass index; $\mathrm{FEV}_{1}$, forced expiratory volume in I second; $\mathrm{RV}$, residual volume; TLC, total lung capacity; DLCO, diffusion capacity for carbon monoxide; 6MWD, 6-minute walk distance; BDI, Baseline Dyspnea Index; HADS, Hospital Anxiety and Depression Scale; $D_{\text {LCO }} / N_{A}, D_{\text {LCO }}$ divided by the alveolar volume.

scores. Therefore, both stepwise multiple regression analyses and PCA suggested that the factors assessed by the CAT were slightly different from those measured by SGRQ.

Jones et $\mathrm{a}^{3,4}$ reported a qualitative study to develop the $\mathrm{CAT}^{3}$ and published the first validation study in $2009 .{ }^{4}$ The authors reported excellent reliability, including internal consistency and repeatability. They also reported the score distribution and its correlation with a COPD-specific version of the SGRQ. ${ }^{24}$ In addition, they published a validation study on the CAT in a large international sample of more than 1,000 patients with COPD. ${ }^{5}$ Gupta et $\mathrm{al}^{25}$ reported good internal consistency with Cronbach's $\alpha$ coefficients of $0.85-0.98$ in a recent systematic review. ${ }^{25}$ The internal consistency result of the CAT in this study is consistent with the findings of previous studies. With respect to univariate correlations between CAT and SGRQ scores, in previous studies, correlation coefficients $(R)$ between CAT and SGRQ total scores were $0.73-0.84,5,23$ while Gupta et $\mathrm{al}^{25}$ reported $0.72-0.74$. Although the correlation coefficient reported herein is lower ( $R=0.668)$, it is close to the bottom end of the range reported by other researchers. This difference might be explained by

Table 7 Correlations of three principal component scores with CAT and SGRQ total scores (Pearson's correlation coefficients)

\begin{tabular}{|c|c|c|c|c|}
\hline & \multicolumn{4}{|c|}{ Correlation with } \\
\hline & \multicolumn{2}{|l|}{ SGRQ total } & \multicolumn{2}{|l|}{ CAT } \\
\hline & $\begin{array}{l}\text { Correlation } \\
\text { coefficient }(R)\end{array}$ & $P$-value & $\begin{array}{l}\text { Correlation } \\
\text { coefficient }(R)\end{array}$ & $P$-value \\
\hline Component I & -0.733 & $<0.001$ & -0.515 & $<0.001$ \\
\hline Component 2 & -0.208 & 0.030 & -0.304 & 0.001 \\
\hline Component 3 & -0.180 & 0.061 & -0.207 & 0.031 \\
\hline
\end{tabular}

Abbreviations: CAT, COPD assessment test; COPD, chronic obstructive pulmonary disease; SGRQ, St George's Respiratory Questionnaire. the characteristics of patients enrolled in this study. This study included outpatients with GOLD 1-4 COPD classifications. In the two previous studies, the authors used a population with more severe COPD (patients in rehabilitation) and a bigger sample from many countries. ${ }^{5,26}$ The small number of study subjects enrolled from a single center is a major limitation of this study and may impact the reliability and validity of the obtained results.

The present cross-sectional analysis also showed that the CAT evaluated the clinical, functional, and psychological aspects of subjects with COPD as well as the SGRQ. In a comparison with previous studies, the correlation coefficient between the CAT and $\mathrm{FEV}_{1}$ (\% pred) was highest in this study $(R=-0.413)$. However, this correlation was inferior to that between airflow limitation and SGRQ scores (Table 1). Correlations of other physiologic, functional, or clinical measurements with SGRQ total scores were superior to those with CAT scores. Therefore, physiologic measures, including airflow limitation, may not be important areas of focus for the CAT.

Factors contributing to CAT scores have not been examined in the literature. Multiple regression analyses revealed that only $37 \%$ of the variance of CAT scores was accounted for by dyspnea assessed by the BDI and psychological factors measured by depression on the HADS scale. On the other hand, dyspnea assessed by the BDI, psychological factors assessed by HADS depression scores, airflow limitation assessed by $\mathrm{FEV}_{1}$, and exercise capacity assessed by $6 \mathrm{MWD}$ accounted for $63 \%$ of the variance in SGRQ total scores. Both dyspnea and psychological factors significantly contributed to both CAT scores and total SGRQ scores. Our results obtained from stepwise multiple regression analyses also indicated that there are other unmeasured factors that explain CAT scores.

PCA was also performed as a data exploration method to seek a way of explaining differences in what SGRQ and CAT measure conceptually. In a comparison between the two scores, component 1 (the pathophysiologic component) was less important for CAT scores. Component 3 (the smoking component) statistically correlated with CAT scores, but not with SGRQ total scores. Thus, a difference of the statistically identified components between SGRQ total scores (components 1 and 2) and CAT scores (components 1,2, and 3) was also demonstrated in this analysis.

The SGRQ was developed as a COPD-specific instrument for measuring health status as reflected by the variety of factors that contribute to SGRQ scores. The CAT is thought to produce similar findings as SGRQ, but item reductions can 
be performed by Rasch analysis. ${ }^{3}$ Although item reduction has been successful in maintaining similar measurement components, the loss of some input might influence the output of these instruments.

There are several limitations in this study that should be noted. First, the responsiveness to change, which is an evaluative property, should be compared because one of the most important reasons for developing questionnaires is their use in measuring changes over time. Unfortunately, the authors encountered difficulty in evaluating responsiveness because this study was performed in a cross-sectional manner for the purpose of investigating the discriminative properties of the questionnaires. Second, this single-center study was limited by the number of patients with COPD enrolled at the study site. However, the study does contain all of the patients with stable COPD followed in this hospital during the study period. It is possible that the small size limited the ability to determine the relationships between the variables using regression analyses. In addition, because the study included predominantly men, generalizations of these results to women with COPD may be unwarranted. Since the number of women with COPD is in fact quite low in Japan, the study reflected the reality of clinical COPD in our population. Finally, in this study, we did not assess important clinical features of COPD such as comorbidities, exacerbations, health care utilization (including hospitalizations, unscheduled visits), and systemic inflammation.

\section{Conclusion}

In conclusion, the CAT has similar discriminative properties as SGRQ, since the reliability and score distribution of both instruments are identical. Therefore, the convenience and simplicity of the CAT may facilitate its use for health status assessments in situations when time is limited. Although the questionnaires are very similar, multiple regression analyses demonstrated that physiologic measures may not be important for the CAT; however, both dyspnea and psychological factors significantly contributed to both CAT scores and total SGRQ scores. PCA revealed a difference in the statistically identified components between SGRQ total scores (components 1 and 2) and CAT scores (components 1,2 , and 3). It should be kept in mind that what is assessed by the CAT may differ slightly from what is being measured using SGRQ.

\section{Acknowledgments}

This study was partly supported by a grant to the Respiratory Failure Research Group from the Ministry of Health, Labor, and Welfare, Japan, and by the NPO Medise in Japan.

\section{Author contributions}

MM contributed as the principal investigator and was involved in the study conception and design, analysis of the results, and writing of the manuscript. Koichi Nishimura and Hiroyuki Taniguchi also helped in analyzing the results and writing the manuscript. Tomoki Kimura, Yasuhiro Kondoh, Kensuke Kataoka, Tomoya Ogawa, Fumiko Watanabe, and Shinichi Arizono aided in executing the study and acquiring data. Kazuhito Nakayasu performed the statistical analysis of the data. Osamu Nishiyama, Kazuyoshi Imaizumi, and Yoshinori Hasegawa helped in data analysis and interpretation and editing of the manuscript. All authors contributed toward data analysis, drafting and critically revising the paper and agree to be accountable for all aspects of the work.

\section{Disclosure}

The authors report no conflicts of interest in this work.

\section{References}

1. Guyatt GH, Berman LB, Townsend M, Pugsley SO, Chambers LW. A measure of quality of life for clinical trials in chronic lung disease. Thorax. 1987;42:773-778.

2. Jones PW, Quirk FH, Baveystock CM, Littlejohns P. A self-complete measure of health status for chronic airflow limitation. The St George's Respiratory Questionnaire. Am Rev Respir Dis. 1992;145:1321-1327.

3. Jones P, Harding G, Wiklund I, Berry P, Leidy N. Improving the process and outcome of care in COPD: development of a standardised assessment tool. Prim Care Respir J. 2009;18:208-215.

4. Jones PW, Harding G, Berry P, Wiklund I, Chen WH, Kline Leidy N. Development and first validation of the COPD Assessment Test. Eur Respir J. 2009;34:648-654.

5. Jones PW, Brusselle G, Dal Negro RW, et al. Properties of the COPD Assessment Test (CAT) in a cross-sectional European study. Eur Respir J. 2011;38:29-35.

6. Vestbo J, Hurd SS, Agusti AG, et al. Global strategy for the diagnosis, management and prevention of chronic obstructive pulmonary disease, GOLD executive summary. Am J Respir Crit Care Med. 2013;187(4):347-365.

7. Kwon N, Amin M, Hui DS, et al. Validity of the Chronic Obstructive Pulmonary Disease Assessment Test (CAT) translated into local languages for Asian patients. Chest. 2013;143:703-710.

8. Tsuda T, Suematsu R, Kamohara K, et al. Development of the Japanese version of the COPD Assessment Test. Respir Investig. 2012;50:34-39.

9. Dodd JW, Hogg L, Nolan J, et al. The COPD assessment test (CAT): response to pulmonary rehabilitation. A multicentre, prospective study. Thorax. 2011;66:425-429.

10. Jones PW, Harding G, Wiklund I, et al. Tests of the responsiveness of the Chronic Obstructive Pulmonary Disease (COPD) Assessment Test TM (CAT) following acute exacerbation and pulmonary rehabilitation. Chest. 2012;142:134-140.

11. Daudey L, Peters JB, Molema J, et al. Health status in COPD cannot be measured by the St George's Respiratory Questionnaire alone: an evaluation of the underlying concepts of this questionnaire. Respir Res. 2010;11:98.

12. Miller MR, Hankinson J, Brusasco V, et al. Standardisation of spirometry. Eur Respir J. 2005;26:319-338.

13. Japan Society of Chest Diseases. The predicted values of pulmonary function testing and arterial blood gas in Japanese. Jpn J Thorac Dis. 2001;39:appendix. Japanese.

14. Arizono $\mathrm{S}$, Taniguchi $\mathrm{H}$, Nishiyama $\mathrm{O}$, et al. Improvements in quadriceps force and work efficiency are related to improvements in endurance capacity following pulmonary rehabilitation in COPD patients. Intern Med. 2011;50:2533-2539. 
15. American Thoracic Society. ATS statement: guidelines for the six minute walk test. Am J Respir Crit Care Med. 2002;166:111-117.

16. Hajiro T, Nishimura K, Tsukino M, Ikeda A, Koyama H, Izumi T. Comparison of discriminative properties among disease-specific questionnaires for measuring health-related quality of life in patients with chronic obstructive pulmonary disease. Am J Respir Crit Care Med. 1998;157: 785-790.

17. Mahler DA, Weinberg DH, Wells CK, Feinstein AR. The measurement of dyspnea. Contents, interobserver agreement, and physiologic correlates of two new clinical indexes. Chest. 1984;85:751-758.

18. Hajiro T, Nishimura K, Tsukino M, Ikeda A, Koyama H, Izumi T. Analysis of clinical methods used to evaluate dyspnea in patients with chronic obstructive pulmonary disease. Am J Respir Crit Care Med. 1998;158 1185-1189.

19. Zigmond AS, Snaith RP. The hospital anxiety and depression scale. Acta Psychiatr Scand. 1983;67:361-370.

20. Hosmer DW, Lemeshow S. Applied Logistic Regression. New York, NY: John Wiley \& Sons; 1989:1-173.
21. Feldt LS, Woodruff DJ, Salih FA. Statistical inferences for coefficient alpha. Appl Psychol Meas. 1987;11:93-103.

22. Meyers LS, Gamst G, Guarino AJ. Principal components and factor analysis. Applied Multivariate Research. Design and Interpretation. Thousand Oaks, CA: SAGE Publications; 2006:465-513.

23. Martelli CM, Nascimento NE, Suaya JA, et al. Quality of life among adults with confirmed dengue in Brazil. Am J Trop Med Hyg. 2011;85: 732-738.

24. Meguro M, Barley EA, Spencer S, Jones PW. Development and validation of an improved, COPD-specific version of the St George Respiratory Questionnaire. Chest. 2007;132:456-463.

25. Gupta N, Pinto LM, Morogan A, Bourbeau J. The COPD assessment test: a systematic review. Eur Respir J. 2014;44:873-884.

26. Ringbaek T, Martinez G, Lange P. A comparison of the assessment of quality of life with CAT, CCQ, and SGRQ in COPD patients participating in pulmonary rehabilitation. COPD. 2012;9:12-15.
International Journal of COPD

\section{Publish your work in this journal}

The International Journal of COPD is an international, peer-reviewed journal of therapeutics and pharmacology focusing on concise rapid reporting of clinical studies and reviews in COPD. Special focus is given to the pathophysiological processes underlying the disease, intervention programs, patient focused education, and self management protocols.

\section{Dovepress}

This journal is indexed on PubMed Central, MedLine and CAS. The manuscript management system is completely online and includes a very quick and fair peer-review system, which is all easy to use. Visit http://www.dovepress.com/testimonials.php to read real quotes from published authors.

Submit your manuscript here: http://www.dovepress.com/international-journal-of-chronic-obstructive-pulmonary-disease-journal 